Article

\title{
The Smart City and the Green Economy in Europe: A Critical Approach
}

\author{
Rosario Ferrara \\ Department of Law, University of Turin, Lungo Dora Siena, 100 A 10153 Torino, Italy; \\ E-Mail: rosario.ferrara@unito.it; Tel.: +39-011-6702561; Fax: +39-011-6702559 \\ Academic Editor: Vincenzo Dovì
}

Received: 10 April 2015 / Accepted: 12 May 2015 / Published: 26 May 2015

\begin{abstract}
It is shown in this article that the current European legislation makes the future progress of smart cities critically dependent on the advancement of the green economy and consequently on the further development of energy efficiency and of renewable energy sources. However, the lack of a clear legal framework capable of transforming the current pledges into binding rules at national level can jeopardize the establishment of a more direct and profitable link between the extensive European legislation on energy and environment, and the harmonious and efficient development of smart cities in Europe.
\end{abstract}

Keywords: smart city; green economy; energy efficiency; renewable energy sources; legal framework; directives; regulations; soft law

\section{Introduction}

The concepts of "smart city" and "green economy", as delineated in European regulations and directives, may sometimes appear to be rather cursory and are sometimes regarded as little more than simple slogans born in the shadow of the economic crisis and destined to disappear, almost without a trace, by the time the crisis is over.

While it is extremely difficult to make predictions in this regard, there might certainly be some elements of truth in this analysis; however it is also evident that today these conceptual categories, defined as values and objectives to be pursued and achieved, are heavily employed in the context of the general policies of the European Union.

Indeed, there are many documents of the European Union that are along these lines. They are often in the form of soft law propositions with the simple aim of introducing medium-long term targets and 
are subsequently followed by more binding regulatory measures, with a view to providing stable provisions to the general principles previously enunciated.

One of them is the document Smart Cities \& Communities [1], issued by the European Commission in 2011, containing the outline of an optimal, virtually perfect model of smart city, in which it is possible to reconcile and combine economy and ecology [2], and in which it is, therefore, possible to implement any necessary synergy between the protection of the environment and the development of new technologies, including policies of environmental sustainability and transformation processes of the urban land [3].

In accordance with the definition that clearly inspired the document of the European Commission quoted above: "A smart city... uses digital technologies to enhance performance and well-being, to reduce costs and resource consumption and to engage more effectively and actively with the citizens. Key smart sectors include transport, energy, health care, water and waste. A smart city should be able to respond faster to urban and global challenges than one with a simple 'transactional' relationship with its citizens".

In other words: "Interest in smart cities is motivated by major challenges, including climate change, economic restructuring, retail and entertainment services moving online, ageing populations, and pressures on public finances". The terms 'intelligent city' and 'digital city' are also used [4].

These simple and concise excerpts taken from the most commonly used definitions show that the issue of smart cities is functionally related to that of environmental policies, and especially of environmental policies at the local level: cities, communities, regions. Thus, structure and governance of smart cities (or of smart communities, if related to wider areas) are based on the institutions of the so-called green economy, which is a key issue.

Indeed, the fundamental project of the green economy is the integration and reconciliation of economic growth and environmental values, as foreseen by the Article 11 of the Treaty on the Functioning of the European Union (TFEU). Consequently, in the papers of the scientific community as well as in EU documents, the smart city is substantially identified with the sustainable city, its smartness coinciding with its sustainability. This is going to become the new paradigm for the most important cities in the world [5], especially in the Western Hemisphere.

In this article, I shall outline the links between the considerable amount of acquis communautaire in the form of regulations, directives and soft law tools related to energy and environment with the vision of a smart city. The necessity of a formal framework to transform the current pledges into binding rules will be examined in the conclusions.

\section{Analysis and Discussion}

The proper frame of reference for smart cities is provided by a number of fundamental EU documents that regard the intelligent and efficient use of energy as the necessary medium-long term objective for the attainment of sustainability. The smart and consequently sustainable city must be capable of limiting the impact of the environmental overload caused by undue expenditure of energy and by an energy mix with a low share of renewable energy content. 
Smart cities have even been predicted to become the future "industrial (or) manufacturing cities" [6], a globalized business model where the renewable energies can play, in a "smart context", an important economic role.

\subsection{Precursory Concepts of the Smart Cities}

While originally focused on ICT, the smart city concept has grown beyond this limited scope to include a better use of resources and a lower amount of emissions, which means more efficient urban transport networks, better waste disposal facilities, and energy-saving ways to light and heat buildings.

Being focused on sustainable mobility in urban environments and increased use of renewable energies the three initiatives contained in the Intelligent Energy Europe Programme (examined more in detail in the next section) have clearly contributed to paving the way to the Launch Conference of the Smart Cities and Communities Initiative by the European Commission in 2011.

From the very beginning, smart cities have been related to sustainability. This has become their most relevant factor of identification. In particular, sustainability has been associated with a greater enjoyment of life - a formulation clearly influenced by important doctrines (especially of French origin) that assert the right to pursue happiness. Indeed, one of the indispensable prerequisites of this right to happiness is the claim to a rational and, in fact, happy organization of the city, capable of adequately combining economy and ecology [7]. In other words a veritable droit à la ville [8], namely the right to a city that considers sustainability the founding character of its identity. It is, therefore, no surprise that Paris is a candidate to become, by 2050, a smart city of European level, a model of city life that has in sustainability (and in the "beauty" that naturally derives from it) its fundamental strength and indispensable identification [9].

The sustainability of the smart city appears to be a direct consequence of the EU strategy "20-20-20", heralding a comprehensive legislation on energy efficiency and production of energy from renewable sources. Its legal basis (i.e., the directives resulting from the common strategy "20-20-20") can be found in two important provisions of the TFEU: article 192, second paragraph, which allows derogations from the ordinary procedure of decision in case of "provisions primarily of a fiscal nature", of measures affecting the environment and of "measures significantly affecting the choice of a Member State between different energy sources and the general structure of its energy supply", and article 194, under which EU policies in the energy sector must take into account "... the need to preserve and improve the environment..." $[10,11]$.

\subsection{A Review of the Relevant European Legislation}

The probably best known measure is the "challenge" launched by the European Union in March 2007 with the fielding of the strategy "20-20-20" (the so-called climate and energy package), albeit in the less binding form of soft law. The Union's aim for the year 2020 is three-fold: reducing greenhouse gases by $20 \%$ (or $30 \%$, provided an international agreement is attained on this issue); reducing energy consumption by $20 \%$ thanks to the gradual increasing of energy efficiency; increasing the share of renewable energy to at least $20 \%$.

The climate and energy package was building on the results of Intelligent Energy Europe Programme, originally adopted in 2003. It foresaw the establishment of a roadmap for the energy 
choices of the European Union and the Member States to the distant 2050. The programme was divided into three main areas:

1. Fostering energy efficiency and the rational use of energy resources (SAVE initiative);

2. Promoting new and renewable energy sources and support energy diversification (ALTENER initiative);

3. Promoting energy efficiency and the use of new and renewable energy sources in the field of the transport (STEER initiative).

Five directives, one decision and one regulation are the most significant legal acts of the European Union that should be considered. They will be listed in chronological sequence.

(a) Directive on the so-called renewable energy sources (2009/28/EC);

It is considered a fundamental directive because it provides a legislative framework for the EU targets for greenhouse gas emission savings, and the production and promotion of energy from renewable sources. Moreover, the aim of the directive is to encourage energy efficiency, energy consumption from renewable sources in line with the overall goal "20-20-20", as well as the improvement of energy supply and the economic stimulation of a dynamic sector in which the European Union is trying to set an example.

Member States must also establish national action plans, which in addition to setting the share of energy from renewable sources in transport, production of electricity and heating by 2020 , must also take into account the impact of other energy efficiency measures on final energy consumption. The aim of these plans is also to establish special procedures for the reform of planning and pricing schemes and of the access to electricity networks from renewable sources.

Cooperation between the Member States is also considered by the directive. The Member States can in fact transfer energy from renewable sources using a statistical accounting system and set up joint projects concerning the production of electricity and heating from renewable sources. This kind of cooperation is also possible with third countries, provided some conditions are satisfied: the electricity must be consumed in the territory of the European Union; after the month of June 2009 the electricity must be produced by a newly constructed installation; the quantity of electricity produced and exported must not benefit from any other support.

In addition, the Member States must ensure access to and operation of the grids. This is an important focus point because it requires the Member States to build the infrastructures necessary for the use of energy from renewable sources in the transport sector. It is hardly necessary to stress the importance of this issue in the context of the policies aiming to promote the smart cities and smart communities.

From a technical point of view, the directive takes into account energy from biofuels and bioliquids, in order to contribute to a reduction of at least $35 \%$ of greenhouse gas emissions. In particular, from the first of January 2017 their share in emissions savings should be increased to $50 \%$. Biofuels and bioliquids should not use raw materials (produced either outside the European Union or within it) from land with high biodiversity value or with high carbon stock. Consequently, to benefit from financial support biofuels and bioliquids must be qualified as "sustainable", in accordance to the criteria of the directive. Again, an important issue for smart communities. 
(b) Directive (2009/29/EC) on emission trading;

(c) Directive (2009/30/EC) (Fuel Quality Directive), with a strong impact on sustainable mobility and consequently on the development of the smart city concept;

(d) Directive (2009/31/EC) on carbon capture and storage;

(e) Decision (2009/406/EC), the so-called Effort Sharing Decision concerning the reduction of greenhouse gas emissions on the basis of solidarity between Member States and of sustainable economic growth across the Union;

(f) Regulation (2009/443/EC) Regulation of $\mathrm{CO}_{2}$ emissions from cars;

These measures were all issued in 2009 , i.e., in the middle of the systemic financial and real economy crisis, in the hope that the green economy may contribute to overcoming it, as maintained also by US President Barack Obama in the immediate aftermath of the global crisis.

(g) Directive (2012/27/EU), which amends Directives 2009/125/EC and 2010/30/EU and repeals Directives 2004/8/EC and 2006/32/EC. This Directive integrates and completes the "package" of European standards issued in 2009.

Indeed this directive provides a broad framework concerning not only energy efficiency sensu stricto, i.e., efficiency in energy use, (heating and cooling, article 14) and in energy transformation, transmission and distribution (article 15, with an important "warning" for the national energy regulatory authorities), but also the compliance with the minimum energy performance requirements of buildings used by public bodies, the energy efficiency obligation schemes, the so-called energy audits and energy management systems, metering and billing information, and so on.

Even the premises are very significant: "Whereas...(3) The conclusions of the European council of 17 June 2010 confirmed the energy efficiency target as one of the headline targets of the Union's new strategy for jobs and smart, sustainable and inclusive growth (Europe 2020 Strategy); in addition: “...(11) This directive...also contributes to meeting the goals set out in the Roadmap for moving to a competitive low carbon economy in 2050, in particular by reducing greenhouse gas emissions from the energy sector, and to achieving zero emission electricity production by 2050" ... "(17) The rate of building renovation needs to be increased, as the existing building stock represents the single biggest potential sector for energy savings. Moreover buildings are crucial to achieving the Union objective of reducing greenhouse gas emissions by 80-90\% by 2050 compared to 1990..." This is, without any doubt, the core of the directive. It has the declared objective to increase the use of renewable energies (especially in the cities) by encouraging the development of financing facilities (such as special contributions [12]).

Chapter IV of the Directive (articles 16-20) on the "Horizontal provisions" includes issues that are of particular importance for the development of smart communities: article 17 concerns "information and training", whereas article 20 is dedicated to "Energy efficiency national fund, financing and technical support”, which acknowledges a key point: “...Member States shall facilitate the establishment of financing facilities, or use of existing ones, for energy efficiency improvement measures to maximise the benefits of multiple streams of financing" (article 20, first paragraph). In other words, and in line with the article 192 (second paragraph), of the Treaty on the Functioning of the European Union, renewable energies will be financially sustainable only if they are economically supported by the Member States and by the European Union as well. 
The Directive establishes a close relationship between the smart city concept and the renewable energy issue, which is an important element of the new green economy. Furthermore, the development of renewable energies, together with a policy of building renovation (as foreseen by the Directive), will increase the number of well-paid jobs and of skilled employment. This does match the anticipated character of smart cities (and of smart communities, clusters and regions): dynamic, well-educated and open to innovation.

Moreover, the smart city will be the ideal urban space where participation and democracy are promoted by the sophisticated interplay of the social actors, including both individuals and collective bodies, like political parties, consumer and environment protection associations, and other stakeholders. This is clearly envisaged by the Directive (art. 17): "Member States shall ensure that information on available efficiency mechanisms and financial and legal frameworks is transparent and widely disseminated to all relevant market actors, such as consumers, builders, architects, engineers, environmental and energy auditors, and installers of building elements."

The Directives 2009/72/EC and 2009/73/EC, as well as the three Regulations 714/2009, 715/2009 and 1775/2005 contained in the Third Energy Package, have also had a beneficial (if indirect) effect on the implementation of the "Europe 2020 Strategy" through a "competitive and sustainable supply of energy to the economy and the society". Indeed, the separation of companies' generation operations from their transmission activities (Three different options (ownership unbundling, independent system operator (ISO) and independent transmission operators (ITO)) are available so that the needs of different national market structures can considered.) has contributed to reducing the market power of the largest energy companies.

The new 2030 framework for climate and energy policies has been agreed upon by the EU Heads of Government in the month of October of 2014, after the publication of a green book by the Commission. In addition to a Green House Gas (GHG) emissions reduction target of $40 \%$, the Policy Framework has set a target of at least $27 \%$ for renewable energy and energy efficiency enhancement by 2030 . These targets are consistent with the Energy Roadmap 2050 set out by the Commission in 2011. However, no legislative act has been issued by the Commission at the date of this publication.

\subsection{An Example of National Implementation: The Italian Case}

As an example of how the European legislation is implemented in the regulations of the Member States, the Italian system is considered. The following key pieces of legislation have been passed by the Italian Parliament in response to European legal acts:

1. Decree Law N. 28/2011, by which the before mentioned Directive 2009/28/EC, has been implemented. It has set the general rules, delegating the detailed norms to a number of Ministerial Decrees issued by the Minister of Economic Development;

i) Ministerial Decree of September 10, 2010, containing the national guidelines for the authorization of plants powered by renewable sources, according to article 12 of Legislative Decree n. 387/2003, which was the general regulation of the matter until the enactment of the Legislative Decree n. 28/2011; 
ii) Ministerial Decree of March 15, 2012 about definition and quantification of regional goals concerning renewable energy sources and the definition of how to handle cases of non-achievement of the objectives by Regions and Autonomous Provinces (Burden Sharing), in compliance with Article 37 of the quoted Legislative Decree n. 28/2011, (definition and quantification of the medium-long term results that Regions and Autonomous Provinces commit to abide by in line with national targets set by 2020);

2. The Presidential Decree of April 16, 2013 on the energy performance certificate, setting rules for the verification of the professional qualification and independence of experts and organizations;

3. Law n. 90 of August 3, 2013, concerning the transposition of the Directive 2010/31/EU on energy performance in buildings into Italian law;

4. Legislative Decree n. 102 of July 4, 2014, implementing the Directive 2012/27/EU on energy efficiency. It provides a framework for concrete measures aimed at the promotion and implementation of the results of efficiency energy as already predetermined by the previously quoted D.M. of 15th March 2012, with a view to achieving the level of energy efficiency foreseen by European Union law.

Moreover, it would be useful to include norms and regulations issued by each Italian Region. However, they are mostly expenditure norms, i.e., provisions of financial support with the aim of encouraging the use of renewable energies by economic operators and consumers [10].

In the other European countries transpositions into national laws went through similar legislative processes in accordance with the national procedures and practices specific to each issue.

In the United Kingdom, for instance, energy is a reserved matter for the Central Government, but the deployment of actual mechanisms for increasing the levels of renewables is a matter for Devolved Administrations. Thus, the Directive 2009/28/EC was implemented through a range of statutory instruments, such as the Renewables Obligation Orders (England and Wales/Scotland/ Northern Ireland) issued by Devolved Authorities and the Feed-in Tariffs Order issued by the Minister of State of the National Government. Similarly, the Directive 2010/31/EU was implemented through the revision of the Housing Act 2004 and of the Energy Performance of Building Regulation 2007, contained in statutory instruments (England and Wales/Scotland/Northern Ireland). The strategy for the renovation of buildings referred to in the Directive 2012/27/EU has been established by the Secretary of State of the Central Government, after consultation with the other competent authorities (Northern Ireland departments, Scottish Ministers, and Welsh Ministers) in the Energy Efficiency (Building Renovation and Reporting) Regulations 2014 (S.I. 2014 No. 952).

\subsection{Looming Difficulties}

No doubt there is an important, definite and stable relationship between the new energy sources and the smart city (and the smart community): indeed a key feature of smartness is the capability of reducing greenhouse gas emissions in the urban spaces (the so-called public spaces).

However, this point of view does not go completely unchallenged. Indeed, it is often claimed that there is not enough evidence underpinning this close identification. For one thing, the renewable energies can prevail over traditional energy sources such as oil and gas only thanks to the generous 
economic contribution of the European Member States. This opinion is shared by the European Union, as is well reflected by the content of the directives examined above.

Indeed subsidies granted to foster the use of renewable energy sources and to reduce greenhouse gas emissions protect the environment, but they introduce a dangerous distortion of the market. A doped market can easily collapse if the subsidies are suddenly lifted as might be the case in the present period of economic crisis. Even a progressive reduction of subsidies to the solar branch has given rise to a serious market disruption of this sector in Germany. The development of shale oil and shale gas extraction technologies, the recent volatility of oil prices, the geopolitical tensions involving major oil producers make predictions all the more unreliable. Thus, it can be wondered if the traditional energies have indeed a short future and how this lapse of time can be actually evaluated.

In other words, there are many important questions waiting for sure and unequivocal answers before the transition to a sustainable development can be reliably predicted. Another matter of concern is the growing tensions within the very environmental movement.

Indeed, most environmental associations have supported from the beginning the choice of new, renewable energies with a view to increasing the protection of the environment. This pragmatic point of view is in accordance with the so-called "shallow ecology", whose utilitarian attitude is criticized by a select minority of environmental associations opposing the use of the new energies for environmental reasons, as they are supposed to give rise to damages to the landscape, to a reduction of global space for agriculture, to a negative view impact, and so on. This is to some extent the natural consequence of a more general ideology, known as "deep ecology". It emphasizes the inherent worth of nature regardless of its instrumental utility to humans [13]. How deep ecology thinking may affect the development of smart cities is as yet unclear. In principle, some of the tenets of deep ecology [14] are not necessarily in conflict with the fundamental characters of smart cities. The complexity/complication argument for instance seems to be well in accordance with the vision of a composite, but well-structured urban space. However, the deep ecology discourse as it is conducted in practice tends to privilege the non-human environment and to become intrinsically "anti-urban".

In addition to the uncertainties mentioned above, it is also necessary to point out some reservations occasionally made against an uncritical, extensive use of the concept of "smart city".

For one thing, the existence of a positive prejudice toward the buildup of smart cities may lead to ignoring alternative urban development strategies for the improvement of the quality of life or, conversely, to underestimate the strong negative effects and consequences that the diffusion of new technologies and of networked infrastructures can occasionally give rise to [15].

\subsection{A Serious Shortcoming: The Absence of a Binding Legal Framework}

The new renewable energies are certainly relevant from a legal perspective: there are European Strategies, as well as European legal acts, especially directives, whose current trends have been analysed in previous sections; and partly as a consequence of this acquis communautaire there are, of course, national norms and rules that regulate projects and objectives, and, first, of all, there are legal definitions of the single energy sources.

On the other hand, is it possible to find, as of the present time, a legal definition for a smart city? Indeed, there exist both European and national strategies, as well as documents concerning the smart 
cities (smart communities, smart regions), but there does not seem to be anything really relevant from the point of view of the law. On the other hand, it is only the law that can legitimate the establishment of compulsory rules for individuals as well as for private and public collective bodies.

In other words, the smart city (regarded as a logical category) is presently relevant and to some extent well-defined only from a sociological point of view.

According to most general reports [16,17], the defining features and factors of a smart city can be classified as follows:

1. Smart economy, which means competitiveness, and consequently entrepreneurial skill, economic image \& trademarks, productivity, flexibility of labour market, ability to innovate, etc.;

2. Smart people, in other words social and human capital, with high levels of qualification, social and ethnic plurality, flexibility and creativity, participation in public life, etc.;

3. Smart governance, which implies participation in decision-making process, availability of public and social services, a transparent governance, good political strategies, and perspectives [18];

4. Smart mobility, with both local and national/international accessibility, for the promotion of sustainable, innovative and safe transports systems;

5. Smart environment, in other words good policies for pollution prevention and environmental protection with a view to increasing the attractiveness of natural conditions and to promoting a sustainable resource management;

6. Smart living, the so-called quality of life, with cultural facilities, good health conditions, housing quality, education facilities, social cohesion, etc.

Indeed, these are all sociological concepts, apt to provide general objectives and general guidelines for the development of good public policies in line with the most general aim to elevate the quality of life in urban spaces.

In other words, it is certainly possible to conceive and design a development path for the future of our cities a development path eventually leading to a scenario close to the smart model, well in accordance with the European roadmap "Europa 2050". However, it is extremely difficult (if not outright impossible) to find, at the same time, some legal trail by which to introduce compulsory tools for the implementation of a "smart" policy (or of several "smart" policies) capable of increasing the overall attractiveness of public urban spaces in Europe.

\section{Conclusions}

The evolution of the concept of "smart city" has gone hand in hand with the growing concern for the protection of the environment, the development of renewable energy sources and with the necessity of increasing the overall quality of urban landscapes including a dynamic social and cultural environment, capable of attracting a well-educated and skilled workforce.

Each single component of this scenario has been the object of an extensive European legislation, whose subsequent implementations in each Member State has given rise to a reasonable legal harmonization. However, no such strategy has been attempted for the definition of smart cities as a whole.

There may be some real hurdles in such an attempt: different physical landscapes, distinctive urban residential cultures, a divergent morphology of infrastructures, contrasting norms, traditions and habits 
at local level. However, the history of European integration has shown that tackling and overcoming difficult tasks has been the key to veritable breakthroughs in the process of Europeanization.

It's time for the scientific community to analyze the development of a suitable legal framework for the European smart cities of the future and for the policy makers at European and national level to adopt the necessary decisions.

\section{Conflicts of Interest}

The author declares no conflict of interest.

\section{References}

1. European Commission. Integrated Sustainable Urban Development, Cohesion Policy 2014-2020; European Commission: Brussels, Belgium, 2012.

2. Morand-Deviller, J. Le juste et l'utile en droit de l'environnement. In Pour un Droit Commun de l'environnement. Mélanges en l'honneur de Michel Prieur; Dalloz: Paris, France, 2007; pp. 263-295.

3. Papa, R. Smart cities: Research, projects and good practices for infrastructures. J. Land Use Mobil. Environ. 2013, 6, 291-292.

4. Su, K.; Li, J.; Fu, H. Smart city and the applications. In Proceedings of the IEEE International Conference on Electronics, Communications and Control (ICECC), Zhejiang, China, 9-11 September 2011; pp. 1028-1031.

5. Kunzmann, K.R. Smart cities: A new paradigm of urban development. CRIOS 2014, 7, 9-19.

6. Gargiulo, C.; Pinto, V.; Zucaro, F. EU smart city governance. J. Land Use Mobil. Environ. 2013, 6, 356-370.

7. Jepson, E.J.; Edwards, M.M. How possible is sustainable urban development? An analysis of planners' perceptions about new urbanism, smart growth and the ecological city. Plan. Pract. Res. 2010, 25, 417-437.

8. Auby, J.B. Droit De La Ville; Lexisnexis: Paris, France, 2013.

9. Vincent Callebaut Architectures. Available online: http://vincent.callebaut.org/page1-imgparissmartcity2050.html (accessed on 27 January 2015).

10. Vivani, C. Ambiente ed energia. In Trattato di Diritto Dell'ambiente; Ferrara, R., Sandulli, M.A., Eds.; Giuffré: Milano, Italy, 2014; p. 503.

11. Ferrara, R. I Principi Comunitari Della Tutela Dell'ambiente; Giappichelli: Torino, Italy, 2006.

12. Ferrara, R. La tutela dell'ambiente. In Trattato Di Diritto Privato Dell'unione Europea; Ajani, G., Benacchio, G.A., Eds.; Giappichelli: Torino, Italy, 2006.

13. Ferrara, R. Etica, ambiente e diritto: Il punto di vista del giurista. In Trattato di Diritto Dell'ambiente; Ferrara, R., Sandulli, M.A., Eds.; Giuffré: Milano, Italy, 2014.

14. Naess, A. The shallow and the deep, long-range ecology movement. A summary. Inquiry 1973, 16, 95-100.

15. Graham, S.; Marvin, S. Telecommunications and the City: Electronic Space, Urban Place; Routledge: London, UK, 1996. 
16. Giffinger, R.; Fertner, C.; Kramar, H.; Kalasek, R.; Pichler-Milanovic, N.; Meijers, E. Smart Cities: Ranking of European Medium-Sized Cities; Vienna University of Technology: Vienna, Austria, 2007.

17. Schönert, M. Städteranking und Imagebildung: Die 20 größten Städte in Nachrichten-und Wirtschaftsmagazinen. BAW Monatsbericht 2003, 2, 1-8.

18. Paskaleva, K.A. Enabling the smart city: The progress of city e-governance in Europe. Int. J. Innov. Reg. Dev. 2009, 1, 405-422.

(C) 2015 by the author; licensee MDPI, Basel, Switzerland. This article is an open access article distributed under the terms and conditions of the Creative Commons Attribution license (http://creativecommons.org/licenses/by/4.0/). 